\title{
Updating the biogeochemical cycle of silicon in the modern ocean
}

PAUL J. TRÉGUER ${ }^{1}$, DR. JILL N SUTTON ${ }^{2}$, BRZEZINSKI MARK $^{3}$, MATT CHARETTE ${ }^{4}$, TIMOTHY DEVRIES ${ }^{3}$, STEPHANIE DUTKIEWICZ ${ }^{5}$, CLAUDIA EHLERT ${ }^{6}$, JON

HAWKINGS $^{7}$, AUDE LEYNAERT ${ }^{1}$, SU MEI LIU ${ }^{8}$, NATALIA LLOPIS MONFERRER ${ }^{9}$, MARIA LOPEZ-ACOSTA ${ }^{10}$, MANUEL MALDONADO ${ }^{11}$, SHAILY RAHMAN ${ }^{12}$, LIHUA RAN $^{13}$ AND OLIVIER ROUXEL ${ }^{14}$

${ }^{1}$ University of Brest, CNRS, IRD, Ifremer, Institut Universitaire Européen de la Mer, LEMAR

${ }^{2}$ European Institute for Marine Studies - UBO

${ }^{3} \mathrm{UCSB}$

${ }^{4}$ WHOI

${ }^{5}$ Massachusetts Institute of Technology

${ }^{6}$ Carl von Ossietzky University of Oldenburg

${ }^{7}$ Florida State University

${ }^{8}$ Frontiers Science Center for Deep Ocean Multi-spheres and Earth System and Key Laboratory of Marine Chemistry Theory and Technology, Ministry of Education, Ocean University of

China

${ }^{9}$ Unversity of Brest

${ }^{10}$ Institute of Marine Research IIM-CSIC

${ }^{11}$ Center for Advanced Studies of Blanes CEAB-CSIC

${ }^{12}$ University of Southern Mississippi, University of Colorado Boulder

${ }^{13}$ Second Institute of Oceanography

${ }^{14}$ Ifremer

Presenting Author: paul.treguer@univ-brest.fr

The element silicon $(\mathrm{Si})$ is required for the growth of silicified organisms in marine environments, such as diatoms. These organisms consume vast amounts of Si together with $\mathrm{N}, \mathrm{P}$, and $\mathrm{C}$, connecting the biogeochemical cycles of these elements. Thus, understanding the $\mathrm{Si}$ cycle in the ocean is critical for understanding wider issues such as carbon sequestration by the ocean's biological pump. Here, we show that recent advances in process studies indicate that total $\mathrm{Si}$ inputs $(14.8 \pm 2.6 \mathrm{Tmol}-\mathrm{Si}$ $\left.\mathrm{yr}^{-1}\right)$ and outputs $\left(15.6 \pm 2.4 \mathrm{Tmol}_{-} \mathrm{Si}_{\mathrm{yr}}{ }^{-1}\right)$, to and from the world ocean, are $57 \%$ and $37 \%$ higher, respectively, than previous estimates. We also update the total ocean silicic acid inventory value, which is about $24 \%$ higher than previously estimated. These changes are significant, modifying factors such as the geochemical residence time of $\mathrm{Si}$, which is now about 8,000 years, two times faster than previously assumed. In addition, we present an updated value of the global annual pelagic biogenic silica production $\left(255 \pm 52 \mathrm{Tmol}_{-} \mathrm{Si}_{\mathrm{yr}}{ }^{-1}\right)$ based on new data from 49 field studies and 18 model outputs, and provide a first estimate of the global annual benthic biogenic silica production due to sponges (6 Tmol-Si $\left.\mathrm{yr}^{-1}\right)$. Given these important modifications, we hypothesize that the modern ocean Si cycle is at approximately steady state with inputs $=14.8( \pm 2.6)$ Tmole-Si $\mathrm{yr}^{-1}$ and ouputs $=15.6( \pm 2.4)$ Tmole-Si $\mathrm{yr}^{-1}$. Potential impacts of global change on the marine Si cycle are discussed. 